\title{
$\gamma \delta$ T Iymphocytes as a first line of immune defense: old and new ways of antigen recognition and implications for cancer immunotherapy
}

\author{
Alessandro Poggi ${ }^{1}$ and Maria Raffaella Zocchi ${ }^{2}$ * \\ 1 Unit of Molecular Oncology and Angiogenesis, IRCCS-AOU San Martino-IST, Genoa, Italy \\ 2 Division of Immunology, Transplants and Infectious Diseases, IRCCS San Raffaele, Milan, Italy
}

\section{Edited by:}

Dieter Kabelitz, Christian-Albrechts University Kiel, Germany

\section{Reviewed by:}

John Stephen Bridgeman, Cellular

Therapeutics $L t d$., UK

Martin Wilhelm, Klinikum Nürnberg, Germany

\section{*Correspondence:}

Maria Raffaella Zocchi, DITID, IRCCS

San Raffaele, Via Olgettina 60, 20132

Milan, Italy

e-mail:zocchi.maria@hsr.it
Among $\gamma \delta \mathrm{T}$ cells, the $\mathrm{V} \delta 1$ subset, resident in epithelial tissues, is implied in the defense against viruses, fungi, and certain hematological malignancies, while the circulating $V \delta 2$ subpopulation mainly respond to mycobacteria and solid tumors. Both subsets can be activated by stress-induced molecules (MIC-A, MIC-B, ULBPS) to produce pro-inflammatory cytokines and lytic enzymes and destroy bacteria or damaged cells. $\gamma \delta \mathrm{T}$ lymphocytes can also recognize lipids, as those associated to $M$. tuberculosis, presented by the CD1 molecule, or phosphoantigens (P-Ag), either autologous, which accumulates in virus-infected cells, or microbial produced by prokaryotes and parasites. In cancer cells, P-Ag accumulate due to alterations in the mevalonate pathway; recently, butyrophilin $3 \mathrm{~A} 1$ has been shown to be the presenting molecule for P-Ag. Of interest, aminobisphosphonates indirectly activate $\mathrm{V} \delta 2 \mathrm{~T}$ cells inducing the accumulation of P-Ag. Based on these data, $\gamma \delta T$ lymphocytes are attractive effectors for cancer immunotherapy. However, the results obtained in clinical trials so far have been disappointing: this review will focus on the possible reasons of this failure as well as on suggestions for implementation of the therapeutic strategies.

Keywords: $\gamma \delta$ T cells, aminobisphosphonate, BTN3A1, NKG2D ligands, ADAM proteins

\section{$\gamma \delta$ T CELLS AND ANTIGEN RECOGNITION}

Human $\gamma \delta \mathrm{T}$ lymphocytes comprise different subsets defined by their T-cell receptor (TCR), the most prominent of which is present in circulating blood, representing 3-5\% of T lymphocytes, and is composed of cells expressing the V $\gamma 9 \mathrm{~V} \delta 2 \mathrm{TCR}$ (V $\delta 2 \mathrm{~T}$ cells). The subset bearing the V $\delta 1$ chain of the TCR is $<1-2 \%$ of circulating $\mathrm{T}$ cells and is mostly represented in the mucosal-associated lymphoid tissue, known to play an important role in the first-line defense against viral, bacterial, and fungal pathogens $(1-5) . \gamma \delta \mathrm{T}$ cells recognize a wide variety of antigens, such as lipids, proteins, and phosphoantigens (P-Ag), without the need of HLA-restricted antigen presentation (6-9): circulating $\mathrm{V} \delta 2 \mathrm{~T}$ lymphocytes are involved in the response to mycobacteria, EBV, and some solid tumors, while resident $\mathrm{V} \delta 1 \mathrm{~T}$ cells contribute to the immunity against Listeria monocytogenes, $\mathrm{CMV}$, and certain hematological malignancies $(2-4,10)$. Both $\gamma \delta \mathrm{T}$-cell subsets can interact with stress-induced MIC-A, MIC-B, and ULBPs; the recognition is mediated through the NKG2D receptor, also expressed by $\alpha \beta T$ lymphocytes $(3,11-13)$. In $\gamma \delta \mathrm{T}$ cells, NKG2D seems to work in association with the TCR that also binds to these stress molecules: upon its engagement, an activating signal is delivered in $\gamma \delta \mathrm{T} \mathrm{lym}-$ phocytes that promptly exert their effector function, by proliferating, producing pro-inflammatory and antimicrobial cytokines, such as interferon-gamma (IFN) $-\gamma$ or tumor necrosis factor (TNF)- $\alpha$, or releasing lytic enzymes to destroy bacteria or infected cells, as a response to damage signals (10-13). A similar mechanism can be exploited by $\gamma \delta \mathrm{T}$ lymphocytes to face transformed cells that also overexpress NKG2D ligands $(-\mathrm{L})$ due to the stress-inducing transformation, like in solid tumors or in hematological malignancies (14-19). Of note, these ligands can also be upregulated at the cell surface by drugs, including all-trans-retinoic acid or sodium valproate, commonly used in anti-leukemic therapeutic schemes, thus improving $\gamma \delta \mathrm{T}$ cell-mediated anti-cancer capacity (20-23). Another potent stimulus for $\gamma \delta \mathrm{T}$ cells of the $\mathrm{V} \delta 2$ subset, acting through the TCR, is represented by low molecular weight P-Ag (4-8). Consistent with the stress-surveillance model, P-Ag may be autologous, such as isopentenylpyrophosphate (IPP), which accumulates in many virus-infected or transformed cells, or microbial, such as hydroxymethyl but-2-enyl pyrophosphate (HMBPP), a metabolic intermediate specific to many prokaryotes and parasites (4-8). Of clinical interest, aminobisphosphonates (N-BPs), which are widely prescribed for osteoporosis and malignancy, indirectly activate $\mathrm{V} \gamma 9 \mathrm{~V} \delta 2$ cells by inhibiting farnesyl-pyrophosphate synthase, which provokes IPP accumulation (24-28).

\section{POSSIBLE ANTIGEN-PRESENTING MOLECULES FOR $\gamma \delta$ T CELLS}

Thus, the types of Ag recognized by $\gamma \delta \mathrm{T}$ lymphocytes may vary in size, composition, and molecular structure, much more than those recognized by $\alpha \beta T$ cells, and include soluble or cell surface proteins, small peptides, phospholipids, prenyl-pyrophosphates, and sulfatides. The mode of antigen recognition by $\gamma \delta \mathrm{T}$ cells has been a controversial issue for several years, as they apparently do not need Ag presentation by specialized cells. The TCR that these lymphocytes are equipped with, display some peculiar features such as a limited diversity compared to the $\alpha \beta T C R$, and a type of interaction 
with the Ag that rather resembles that of the B-cell receptor. This hypothesis is based on structural and functional findings: indeed, CDR3 regions of the $\gamma \delta$ TCR resemble immunoglobulin (Ig) CDRs in terms of length and variability, as the TCR $\delta$ and $\gamma$ chain have long or short CDR3, respectively, as is the case of Ig heavy and light chains $(29,30)$. In contrast, length and conformation of TCR $\alpha$ and $\beta$ CDR3s are similar to each other, which may be a requirement for the docking on the surface of MHC molecules and the recognition of MHC-bound peptides. In some cases, however, small Ag may be presented to $\gamma \delta \mathrm{T}$ cells as well, in general in the case of soluble small molecules unable to induce a TCR cross-linking (31). A still unsolved question seems to be the Ag-presenting molecule recognized by $\gamma \delta \mathrm{T}$ cells. In mice, the non-classical or truncated MHC molecules T10/T22, not constitutively expressed at the cell surface but induced by stress signals, have been shown to bind to $\gamma \delta \mathrm{TCR}$, that makes an angle using CDR3 $\delta$ amino-acid side chains for the interaction $(32,33)$.

Other structures described to be potentially responsible for $\mathrm{Ag}$ presentation to $\gamma \delta \mathrm{T}$ cells are the group $1 \mathrm{CD} 1$ molecules. CD1 comprises a family of non-polymorphic genes located outside the MHC complex and encodes proteins structurally related to MHC class-I molecules $(34,35)$. In humans, products of four of the five CD1 genes, designated CD1a, CD1b, CD1c, and CD1d, have been identified as type 1 integral membrane proteins associated with $\beta 2$-microglobulin and are expressed on antigen-presenting cells. A direct evidence for CD1 proteins as antigen-presenting molecules was provided by isolation of a human $\mathrm{CD}^{-}{ }^{-} \mathrm{CD} 8^{-}$T-cell line that proliferated in response to $M$. tuberculosis-derived antigens: the purification of the CD1b-restricted antigens revealed a subset of mycolic acids, a family of free fatty acids present in the outer cell wall of mycobacteria and several other bacteria. Soon after, some glycolipids, such as phosphatidylinositol-containing lipoglycans and glycosylated mycolates, that are also associated with the mycobacteria cell wall, were identified as CD1b-presented antigen $(36,37)$. The CD1-restricted presentation of lipid and glycolipid antigens to $\mathrm{T}$ cells was strengthened by the threedimensional structure of the mouse CD1d protein determined by X-ray crystallography $(35,38)$, showing a putative antigenbinding groove, which is remarkably different from that found in MHC molecules. Subsequent characterization of mycobacteriaderived antigens revealed a remarkable ability of human group 1 CD1 (CD1a, CD1b, CD1c) to mediate presentation of lipid and glycolipid antigens to $\mathrm{T}$ cells, including $\gamma \delta \mathrm{T}$ cells.

It has been unknown for many years whether and how prenylpyrophosphates are presented to $\gamma \delta \mathrm{T}$ cells. In the last two years, a number of papers have been published identifying butyrophilin (BTN)3A1 as the molecule that can directly bind P-Ag for presentation. BTNs are type 1 trans-membrane molecules containing two Ig-like domains in their extracellular portion (39). Some BTNs carry a B30.2 domain. In humans, the BTNs genes are clustered on chromosome 6 in the MHC class-I region containing three related genes: BTN3A1, BTN3A2, and BTN3A3 $(40,41)$. The former molecule seems the only one containing a B30.2 domain, forming a basic pocket, which is essential for N-BPs-mediated activation of $\gamma \delta$ T cells, although the authors did not show evidence for direct binding of P-Ag to BTN3A1 (40). More recently, such direct binding has been demonstrated to occur to the V-like domain of
BTN3A1 and the complex has been crystallized (42). It is still not clear how intracellularly generated P-Ag (e.g., those derived upon $\mathrm{N}$-BPs treatment) can be associated to BTN3A1: one possibility is that $\mathrm{P}-\mathrm{Ag}$ are secreted and then bind to the basic groove of BT3A1 or, alternatively, the B30.1 basic domain binds to P-Ag with low affinity and induces a conformational change in the external portion of the molecule that, in turn, is recognized by $\gamma \delta \mathrm{T}$ cells (39, 42, 43).

\section{$\gamma \delta$ T CELLS AND ANTI-CANCER SURVEILLANCE}

Since their discovery in the late 1980 s, $\gamma \delta$ T cells have been extensively studied and different characteristics, including MHCunrestricted cytotoxic activity against malignant cells, have made these cells a promising potential therapeutic tool $(3,4,10,15$, $44-46)$. It is now clear that $\gamma \delta \mathrm{T}$ lymphocytes are good mediators of a stress-related response: for example, they can recognize directly stress-induced ligands, such as MIC-A, MIC-B, or ULBPs, through the NKG2D receptor or be activated by P-Ag derived by the isoprenoid pathway used by several microorganisms or by the mevalonate pathway in infected or transformed cells (14). However, NKG2D-L can be released, due to the action of the disintegrin-and-metalloproteinases ADAM10/17 or the disulfideisomerase ERp5, overexpressed in solid and hematologic tumors (47-52). In their soluble form (sNKG2D-L), these ligands hinder the recognition of membrane-bound MIC-A/B or ULBPs by NKG2D receptor; in turn, sNKG2D-L are not able to trigger an activating signal in effector lymphocytes that cannot exert their anti-tumor activity (46-51). Moreover, serum levels of sNKG2D$\mathrm{L}$ have been related to the outcome and progression of several neoplastic diseases $(18,23,52-54)$.

$\gamma \delta \mathrm{T}$ cells can also be indirectly activated by pro-inflammatory cytokines or by toll-like receptors (TLR) that bind to viral or bacterial products (1-4). Another activation signal can be delivered via CD16 through the interaction with the Fc of IgG: this binding initiate the antibody-dependent cell cytotoxicity (ADCC) exerted to destroy opsonized cells or microorganisms (2). Upon one of the mentioned stimuli, $\gamma \delta$ T lymphocytes expand, acquire cytotoxic function, and secrete an array of Th1 pro-inflammatory cytokines, such as IFN- $\gamma$ or TNF- $\alpha$. Another important feature of T lymphocytes expected to interact with cancer cells is their capacity to infiltrate tumors. Accordingly, tumor-infiltrating gamma delta $\mathrm{T}$ lymphocytes were detected in a broad spectrum of malignancies $(2-4,10)$.

For all these aspects of their function, $\gamma \delta$ T cells have been considered attractive for anti-cancer therapies: of note, ADCC can be exploited by the use of therapeutic monoclonal antibodies (mAbs) $(44,45,55)$. In addition, various selective agonists, including P-Ag, for human $\gamma \delta \mathrm{T}$ lymphocytes have been synthesized, allowing the launch of several clinical trials for patients with follicular lymphoma, multiple myeloma (MM), and acute myeloid leukemia, as well as non-hematological malignancies, such as renal cell (RCC), breast, and prostate carcinomas.

\section{EVALUATION OF $\gamma \delta$ T CELL-BASED CLINICAL TRIALS}

Given the demonstrated in vitro anti-cancer activity of $\gamma \delta \mathrm{T}$ cells and their in vivo potential as anti-tumor effectors, numerous clinical trials have been performed in the last years to exploit the 
properties of these cells for cancer immunotherapy (44, 56-64). Two methods have been applied so far: adoptive transfer of autologous $\gamma \delta \mathrm{T}$ lymphocytes expanded in vitro and then reinfused to patients and direct administration of drugs or substances able to stimulate $\gamma \delta \mathrm{T}$ cells in vivo $(44,56-58)$. The in vitro stimulation and expansion of this cell population is achievable using P-Ag, N-BPs, or immobilized anti- $\gamma \delta$ TCR antibodies, and allows the optimization and control of the effector cells obtained $(7,8$, 24, 56). However, this method requires specialized laboratories and expertise and is rather expensive. In turn, the administration of N-BPs or synthetic P-Ag in combination with cytokines has been used as a cheaper and straight-forward therapeutic alternative. The third generation of N-BPs as zoledronate is the most commonly used for both in vitro activation and in vivo administration; the $\mathrm{EC}_{50}$ for $\gamma \delta \mathrm{T}$ cells is favorable $(0.003 \mu \mathrm{M})$ and a single dose of $4 \mathrm{mg}$ leads to plasma levels (1-5 $\mu \mathrm{M})$ shown to be effective in activating $\gamma \delta \mathrm{T}$ cells in vitro $(56,60)$. As an alternative, the synthetic phosphate-containing molecule bromohydrin pyrophosphate (BrHPP) is used for either in vitro expansion or in vivo stimulation of $\gamma \delta \mathrm{T}$ lymphocytes and also upregulates their ability to mediate rituximab-induced $\operatorname{ADCC}(56,61)$. Together with zoledronate or BrHPP, interleukin-2 is used for in vitro expansion of this T-cell population, and also added to the therapeutic schemes in different cancers; however, IL-2 is toxic at high doses (those that are commonly effective), leading to vascular leakage, hyperpyrexia, severe hypotension whereas low, and well-tolerated doses are much less effective in vivo $(28,56)$.

A preliminary pilot study by Wilhelm's team examined toxicity, in vivo activation of $\gamma \delta \mathrm{T}$ cells, and anti-lymphoma efficacy of pamidronate/IL-2 in 19 patients with relapsed/refractory lowgrade non-Hodgkin lymphomas (NHL) or MM (44). The authors demonstrated that pamidronate administered with low-dose IL2 is well tolerated and induces a specific $\gamma \delta \mathrm{T}$-cell expansion; furthermore, the clinical response observed in the patients, i.e., stabilization or partial response, is linked to $\gamma \delta \mathrm{T}$-cell proliferation in vivo. A second study was reported by Dieli's group, showing that zoledronate induced the in vivo development of $\mathrm{V} \gamma 9 \mathrm{~V} \delta 2$ cells producing IFN- $\gamma$ and exerting strong anti-tumor responses (62). Therefore, a pilot study on the effects of zoledronate and IL-2 was conducted in the United States by Malkovsky's group in 12 patients with metastatic RCC (63). Adverse events typical of IL2 monotherapy were observed in all patients, without partial or complete responses. In the following years, phase-I clinical trials were performed in metastatic hormone-refractory prostate cancer and in several patients with solid tumors using BrHPP (56, 64). Given BrHPP's safety profile, a multicentric phase-II study using the drug was launched in relapsed follicular lymphoma patients who had previously received previous lines of therapy, using rituximab at least once $(56,61)$. The treatment induced strong and specific amplification of TCRV $\gamma 9 \mathrm{~V} \delta 2 \mathrm{~T}$ lymphocytes showing a Th1 and cytotoxic effector-memory cell profile (IFN- $\gamma$ and TNF- $\alpha$ production), expressing Fc $\gamma$ RIIIa (CD16) and displaying rituximab-mediated $\operatorname{ADCC}(56,61)$. The combination of BrHPP and rituximab in immunotargeted therapy produced very encouraging results, particularly for follicular lymphoma patients with unfavorable Fc $\gamma$ RIIIa gene polymorphisms (F/F or V/F, 95\% of the patients). Thus, the initial evaluation of clinical trials leads to the conclusion that $\gamma \delta \mathrm{T}$ cell-based immunotherapy is more effective in hematological rather than in solid tumors.

\section{POSSIBLE IMPROVEMENT OF $\gamma \delta T$ CELL-BASED IMMUNOTHERAPY}

In the above cited review by Fisher and coworkers (56), 12 clinical trials involving 157 patients have been analyzed for the evaluation of the efficacy and/or failure of $\gamma \delta \mathrm{T}$ cell-based immunotherapy, and some conclusions can be drawn. First, patients with solid tumors have been treated mostly with adoptive $\gamma \delta$ T-cell transfer, while patients with hematological cancers were mainly treated with $\gamma \delta \mathrm{T}$ cell-expanding drugs. Second, as the trials reviewed were either phase-I, phase-II, or feasibility studies, all patients had already received previous treatments, as chemotherapy or other types of immunotherapy (IL-2 alone). Moreover, in some trials testing $\gamma \delta \mathrm{T}$ cell-stimulating drugs, the combination with IL-2 led to high toxicity with low therapeutic effects. In adoptive transfer studies, different culture conditions and times as well as distinct cell sources (leukapheresis vs. peripheral blood), represent additional variables that render difficult the overall evaluation of the efficacy of these treatments. As the in vitro expansion of $\gamma \delta \mathrm{T}$ lymphocytes is feasible and efficient, an accepted conclusion is that leukapheresis in general is not needed to obtain a sufficient amount of activated effectors to reinfuse. Some evidences emerge from the comparison of clinical responses to $\gamma \delta \mathrm{T}$ cell-immunotherapy with standard-of-care second-line therapies in three selected cancer types, RCC, non-small cell lung carcinoma (NSCLC), and prostate cancer. The proportion of objective responses among patients treated with $\gamma \delta \mathrm{T}$ cell-based immunotherapy is higher than that achieved with recommended second-line therapy in advanced prostate cancer $(33.3 \%$ with $\gamma \delta \mathrm{T}$ cells vs. $25.2 \%$ with prednisolone + docetaxel) and advanced RCC (4.8\% with $\gamma \delta \mathrm{T}$ cells vs. 1.8 with everolimus), but not in advanced NSCLC (7.6\% with erlotinib, $12.2 \%$ with docetaxel, $0 \%$ with $\gamma \delta \mathrm{T}$ cells) $(56,65-$ $67)$. In general, the clinical response to $\gamma \delta \mathrm{T}$-cell immunotherapy in solid tumors is disappointing. There are several possible explanations for this and we will try to consider some of them. First, there might be a considerable difference in $\gamma \delta \mathrm{T}$-cell expansion capacity among patients, patients with hematologic malignancies being more responsive that those with solid tumors (44, 56-64). A considerable inter-individual variation in expansion capacity has been observed among patients with MM, NHL, or chronic lymphocytic leukemia (CLL) with an inverse correlation between the frequency of circulating regulatory $\mathrm{T}$ cells and the ability of $\gamma \delta \mathrm{T}$ cells from cancer patients to proliferate in response to $\mathrm{P}-\mathrm{Ag}$ $(44,56-64)$. Another possible inhibiting factor is represented by transforming growth factor (TGF) $\beta$ that is known to decrease the NKG2D expression on lymphocytes reducing their activation (52, $68,69)$. Moreover, sNKG2D-L released by cancer and accessory cells in the tumor microenvironment can impede the interaction of effector lymphocytes with tumor target cells. (48-52) In addition, other inhibiting signals, such as that delivered by PD-1 or via CTLA-4, can lead to a general inhibition of $\gamma \delta \mathrm{T}$-cell function at the tumor site $(70,71)$. Thus, a possible strategy to overcome inhibitory signals would be the use of mAbs blocking either CTLA4 , such as ipilimumab, or PD-1 or neutralizing TGF $\beta$ (56, 6971 ). In addition, inhibiting the enzymes responsible for sNKG2D 
ligands, including ADAM10 and ADAM17 (71-76), with specific compounds, would push the balance toward $\gamma \delta \mathrm{T}$-cell activation; along this line, the combination of stimulating molecules, such as bisphosphonates, and therapeutic tumor-targeting antibodies, as the anti-CD20 rituximab or the anti-ERBB2 trastuzumab, should improve the efficacy of $\gamma \delta$ T-cell anti-tumor effect $(56,58)$. A different immunoevasion mechanism exerted by tumor microenvironment may be represented by mesenchymal stromal cells (MSC) that are known to down-regulate T-cell effector functions $(77,78)$. We recently reported that LN-MSC derived from NHL patients impair the anti-tumor activity of V $82 \mathrm{~T}$ lymphocytes, selectively inhibiting NKG2D-mediated lymphoma cell killing (79). Of note, $\mathrm{N}-\mathrm{BPs}$ can prevent this effect by reducing TGF $\beta$ and increasing IL-15 production by LN-MSC, and drive the differentiation of V82 T lymphocytes into effector-memory cells producing Th1type cytokines (79). Moreover, N-BPs do not alter the efficiency of V82 T cells to exert rituximab-mediated ADCC. To be successful, $\gamma \delta \mathrm{T}$ cell-based cancer immunotherapy will require protocols updated to limit most of the different immunoescape mechanisms occurring at the tumor site.

\section{PERSPECTIVES}

Response rates to $\gamma \delta \mathrm{T}$ cell-based immunotherapy, either as adoptive transfer or as stimulating drugs, are not satisfactory $(10 \%$ of objective responses); however, about $39 \%$ of patients achieved disease stabilization, indicating a clinical benefit and suggesting the possibility of improving the efficiency of such therapeutic tool $(56,58,80)$. Advantages of this type of anti-cancer therapy would be the safety of drugs and substances known to stimulate $\gamma \delta \mathrm{T}$ cells, beside their efficiency in $\gamma \delta \mathrm{T}$-cell stimulation.

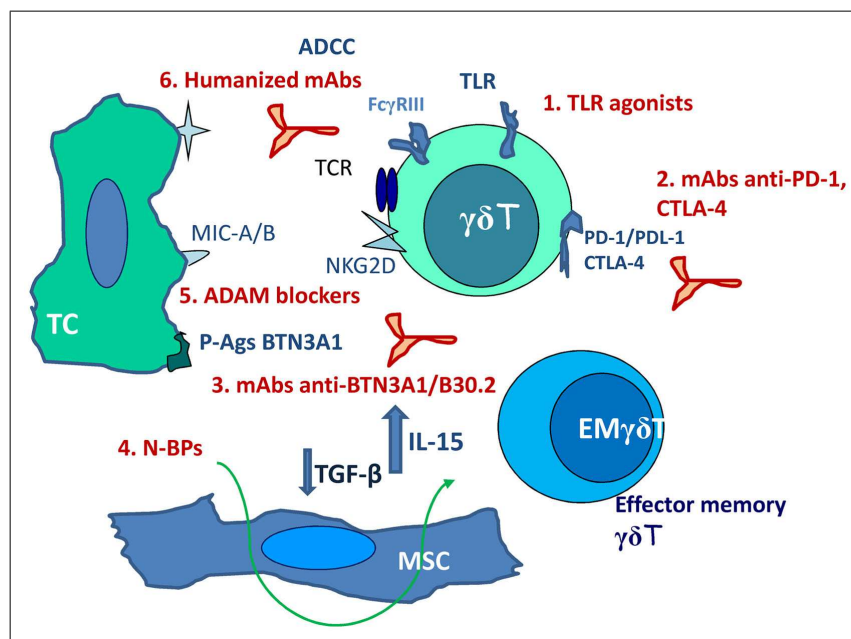

FIGURE 1 | Scheme of possible combinations of activating and inhibiting stimuli aimed to potentiate $\gamma \delta T$-cell anti-cancer response. 1. TLR agonists (imiquimod or resiquimod). 2. mAbs blocking PD-1, PDL-1, and CTLA-4. 3. mAbs directed to the B30.2 basic domain of BTN3A1. 4. N-BPs not only as $\gamma \delta$ T-cell stimulating agents but as immunomodulating drugs (decrease TGF- $\beta$ and increase IL-15 production by LN-MSC). 5. ADAMs specific and non-toxic inhibitors. 6. Humanized mAbs directed against tumor antigens (rituximab, trastuzumab). TC, tumor cell; EM, effector memory; MSC, mesenchymal stromal cells; ADCC, antibody-dependent cellular cytotoxicity.
Drawbacks are mainly represented by immunoevasion. This can be counteracted (Figure 1) by including in the therapeutic protocols non-specific stimulators as TLR agonists (imiquimod or resiquimod) or the BCG vaccine (81). Recently approved clinical trials include mAbs blocking PD-1, PDL-1, and CTLA-4 (58, 70, 71) aimed to inhibit negative signals. Cancer-specific TCR gene transfer has been proposed in the last years to gain efficiency and specificity in the anti-cancer response; $\alpha \beta T C R$ engineered $\gamma \delta \mathrm{T}$ cells have been shown to exert anti-tumor activity in vitro and may be considered as an alternative strategy for adoptive T-cell transfer $(82,83)$.

The recent identification of BTN3A1 as an essential molecule in P-Ag presentation to $\gamma \delta \mathrm{T}$ cells opens new possible ways of interventions: both stimulating and inhibiting $\mathrm{mAbs}$ directed to the B30.2 basic domain of the molecule have been described (39-41, 84). These antibodies might be used differently to induce or regulate $\gamma \delta \mathrm{T}$-cell response to P-Ag, representing an additional tool in the design of immunotherapeutic protocols.

In addition, we propose the use of N-BPs not only as $\gamma \delta \mathrm{T}$-cell stimulating agents but as immunomodulating drugs (79). Finally, the development of ADAMs specific and non-toxic inhibitors would contribute to the improvement of NKG2D-mediated recognition of stress-induced molecules at the surface of tumor cells. Thus, such combined therapeutic protocols, including stimulating molecules, mAbs, and inhibitory substances acting on enzymes, which favor tumor immunoevasion, may represent the new frontier of anti-cancer immunotherapy.

\section{REFERENCES}

1. Hayday A, Tigelaar R. Immunoregulation in the tissues by gammadelta T cells. Nat Rev Immunol (2003) 3:233-42. doi:10.1038/nri1030

2. Hannani D, Ma Y, Yamazaki T, Déchanet-Merville J, Kroemer G, Zitvogel L. Harnessing $\gamma \delta \mathrm{T}$ cells in anticancer immunotherapy. Trends Immunol (2012) 33:199-206. doi:10.1016/j.it.2012.01.006

3. Hayday AC. Gammadelta T cells and the lymphoid stress-surveillance response. Immunity (2009) 31:184-96. doi:10.1016/j.immuni.2009.08.006

4. Bonneville M, O’Brien RL, Born WK. Gammadelta T cell effector functions: a blend of innate programming and acquired plasticity. Nat Rev Immunol (2010) 10:467-78. doi:10.1038/nri2781

5. Komori HK, Meehan TF, Havran WL. Epithelial and mucosal gammadelta T cells. Curr Opin Immunol (2006) 18:534-8. doi:10.1016/j.coi.2006.06.001

6. Constant P, Davodeau F, Peyrat MA, Poquet Y, Puzo G, Bonneville M, et al. Stimulation of human gammadelta $\mathrm{T}$ cells by nonpeptidic mycobacterial ligands. Science (1994) 264:267-70. doi:10.1126/science.8146660

7. Das H, Wang L, Kamath A, Bukowski JF. V $\gamma 9$ V $\delta 2$ T-cell receptor-mediated recognition of aminobisphosphonates. Blood (2001) 98:1616-8. doi:10.1182/blood. V98.5.1616

8. Gober HJ, Kistowska M, Angman L, Jenö P, Mori L, De Libero G. Human T cell receptor gammadelta cells recognize endogenous mevalonate metabolites in tumor cells. J Exp Med (2003) 197:163-8. doi:10.1084/jem.20021500

9. Morita CT, Jin C, Sarikonda G, Wang H. Nonpeptide antigens, presentation mechanisms, and immunological memory of humanVgamma2Vdelta2 T cells: discriminating friend from foe through the recognition of prenyl pyrophosphate antigens. Immunol Rev (2007) 215:59-76. doi:10.1111/j.1600-065X.2006. 00479.x

10. Ferrarini M, Ferrero E, Dagna L, Poggi A, Zocchi MR. Human gammadelta T cells: a nonredundant system in the immune-surveillance against cancer. Trends Immunol (2002) 23:14-7. doi:10.1016/S1471-4906(01)02110-X

11. Kono H, Rock KL. How dying cells alert the immune system to danger. Nat Rev Immunol (2008) 8:279-89. doi:10.1038/nri2215

12. González S, López-Soto A, Suarez-Alvarez B, López-Vázquez A, López-Larrea C. NKG2D ligands: key targets of the immune response. Trends Immunol (2008) 29:397-403. doi:10.1016/j.it.2008.04.007 
13. Champsaur M, Lanier LL. Effect of NKG2D ligand expression on host immune responses. Immunol Rev (2010) 235:267-85. doi:10.1111/j.0105-2896.2010. 00893.x

14. Groh V, Rinehart R, Secrist H, Bauer S, Grabstein K, Spies T. Broad tumorassociated expression and recognition by tumor-derived gammadelta $\mathrm{T}$ cells of MICA and MICB. Proc Nat Acad Sci U S A. (1999) 96:6879-84. doi:10.1073/ pnas.96.12.6879

15. Nausch N, Cerwenka A. NKG2D ligands in tumor immunity. Oncogene (2008) 27:5944-58. doi:10.1038/onc.2008.272

16. Salih HR, Antropius H, Gieseke F, Lutz SZ, Kanz L, Rammensee HG, et al. Functional expression and release of ligands for the activating immunoreceptor NKG2D in leukemia. Blood (2003) 102:1389-96. doi:10.1182/blood-2003-010019

17. Street SE, Hayakawa Y, Zhan Y, Lew AM, MacGregor D, Jamieson AM, et al. Innate immune surveillance of spontaneous B cell lymphoma by natural killer and gammadelta T cells. J Exp Med (2004) 199:879-84. doi:10.1084/jem. 20031981

18. Poggi A, Venturino C, Catellani S, Clavio M, Miglino M, Gobbi M, et al. Vdelta 1 T lymphocytes from B-CLL patients recognize ULBP3 expressed on leukemic B cells and up-regulated by trans-retinoic acid. Cancer Res (2004) 64:9172-9. doi:10.1158/0008-5472.CAN-04-2417

19. Catellani S, Poggi A, Bruzzone A, Dadati P, Ravetti JL, Gobbi M, et al. Expansion of Vdeltal T lymphocytes producing IL-4 in low-grade non-Hodgkin lymphomas ex pressing UL-16-binding proteins. Blood (2007) 109:2078-85. doi:10.1182/blood-2006-06-028985

20. Armeanu S, Bitzer M, Lauer UM, Venturelli S, Pathil A, Krusch M, et al. Natural killer cell-mediated lysis of hepatoma cells via specific induction of NKG2D ligands by the histone deacetylase inhibitor sodium valproate. Cancer Res. (2005) 65:6321-9. doi:10.1158/0008-5472.CAN-04-4252

21. Diermayr S, Himmelreich H, Durovic B, Mathys-Scheeberger A, Siegler U, Lagenkamp U, et al. NKG2D ligand expression in AML increases in response to HDAC inhibitor valproic acid and contributes to allorecognition by NKcell lines with single KIR-HLA class I specificities. Blood (2008) 111:1428-36. doi:10.1182/blood-2007-07-101311

22. Butler JE, Moore MB, Presnell SR, Chan HW, Chalupny NU, Lutz CT. Proteasome regulation of ULBP1 transcription. J Immunol (2009) 182:6600-9. doi:10.4049/jimmunol.0801214

23. Poggi A, Catellani S, Garuti A, Pierri I, Gobbi M, Zocchi MR. Effective in vivo induction of NKG2D ligands in acute myeloid leukaemias by all-trans-retinoic acid or sodium valproate. Leukemia (2009) 23:641-8. doi:10.1038/leu.2008.354

24. Kunzmann V, Bauer E, Wilhelm M. Gamma/delta T-cell stimulation by pamidronate. $N$ Engl J Med (1999) 3440:737-8. doi:10.1056/ NEJM199903043400914

25. Kunzman V, Bauer E, Feurle J, Weissinger F, Tony HP, Wilhelm M. Stimulation of gammadelta $\mathrm{T}$ cells by aminobiphosphonates and induction of anti-plasma cell activity in multiple myeloma. Blood (2000) 96:384-92.

26. Dieli F, Gebbia N, Poccia F, Caccamo N, Montesano C, Fulfaro F, et al. Induction of gammadelta $\mathrm{T}$ lymphocyte effector functions by bisphosphonate zolendronic acid in cancer patients in vivo. Blood (2003) 102:2310-1. doi:10.1182/blood-2003-05-1655

27. Mariani S, Muraro M, Pantaleoni F, Fiore F, Nuschak B, Peola S, et al. Effector gammadelta $\mathrm{T}$ cells and tumor cells as immune targets of zolendronic acid in multiple myeloma. Leukemia (2005) 19:664-70.

28. Bennouna J, Bompas E, Neihardt EM, Rolland F, Philip I, Galea C, et al. PhaseI study of Innacell gammadelta, an autologous cell-therapy product highly enriched in gamma9delta2 $\mathrm{T}$ lymphocytes, in combination with IL-2, in patients with metastatic renal cell carcinoma. Cancer Immunol Immunother (2008) 57:1599-609. doi:10.1007/s00262-008-0491-8

29. Rock EP, Sibbald PR, Davis MM, Chien YH. CDR3 length in antigen-specific immune receptors. J Exp Med (1994) 179:323-8. doi:10.1084/jem.179.1.323

30. Born WK, Aydintug MK, O’Brien RL. Diversity of $\gamma \delta$ T-cell antigens. Cell Mol Immunol (2013) 10:13-20. doi:10.1038/cmi.2012.45

31. Morita CT, Beckman EM, Bukowsli JF, Tanaka Y, Band H, Bloom BR, et al. Direct presentation of non-peptide prenyl pyrophosphate antigens to human $\gamma \delta$ T cells. Immunity (1995) 3:495-507. doi:10.1016/1074-7613(95)90178-7

32. Wingren C, Crowley MP, Degano M, Chien YH, Wilson IA. Crystal structure of a $\gamma \delta$ T cell receptor ligand T22: a truncated MHC-like fold. Science (2000) 287:310-4. doi:10.1126/science.287.5451.310
33. Adams EJ, Chien Y-H, Garcia KC. Structure of a $\gamma \delta \mathrm{T}$ cell receptor in complex with the non-classical MHC T22. Science (2005) 308:252-5. doi:10.1126/ science. 1106885

34. Sugita M, Brenner MB. T lymphocyte recognition of human group 1 CD1 molecules: implications for innate and acquired immunity. Semin Immunol (2000) 12:511-6. doi:10.1006/smim.2000.0277

35. Porcelli SA. The CD1 family: a third lineage of antigen-presenting molecules. Adv Immunol (1995) 59:1-98. doi:10.1016/S0065-2776(08)60629-X

36. Sieling PA, Chatterjee D, Porcelli SA, Prigozy TI, Mazzacaro RJ, Soriano T, et al. CD1-restricted T cell recognition of microbial lipoglycan antigens. Science (1995) 269:227-30. doi:10.1126/science.7542404

37. Moody DB, Reinhold BB, Guy MR, Beckman EM, Frederique DE, Furlong ST, et al. Structural requirements for glycolipid antigen recognition by CDlb-restricted T cells. Science (1997) 278:283-6. doi:10.1126/science.278. 5336.283

38. Zeng Z, Castano AR, Segelke B-W, Stura EA, Peterson PA, Wilson IA. Crystal structure of mouse CD1: an MHC-like fold with a large hydrophobic groove. Science (1997) 277:339-45. doi:10.1126/science.277.5324.339

39. Kabelitz D. Critical role of butyrophilin $3 \mathrm{~A} 1$ in presenting prenyl pyrophosphate antigens to human $\gamma \delta \mathrm{T}$ cells. Cell Mol Immunol (2014) 11:117-9. doi: $10.1038 / \mathrm{cmi} .2013 .50$

40. Harly C, Guillaume Y, Nedellec S, Peigné CM, Monkkonen H, Monkkonen J, et al. Key implication of CD277/butyrophilin-3 (BTN3A) in cellular stress sensing by a major human $\gamma \delta$ T cell subset. Blood (2012) 120:2269-79. doi:10.1182/blood-2012-05-430470

41. Wang H, Henry O, Distefano MD, Wang YC, Raikkonen J, Monkkonen J, et al. Butyrophilin 3Al plays an essential role in prenyl pyrophosphate stimulation of human V $\gamma 2$ V 22 T cells. J Immunol (2013) 191:1029-42. doi:10.4049/jimmunol. 1300658

42. Vavassori S, Kumar A, Wan GS, Ramanjaneyulu GS, Cavallari M, El Daker S, et al. Butyrophilin 3Al binds phosphorylated antigens and stimulates human $\gamma \delta$ T cells. Nat Immunol (2013) 14:908-16. doi:10.1038/ni.2665

43. Sandstrom A, Peigné CM, Léger A, Crooks JE, Konczak F, Gesnel MC, et al. The intracellular B30.2 domain of butyrophilin 3A1 binds phosphoantigens to mediate activation of human V $\gamma 9 \mathrm{~V} \delta 2 \mathrm{~T}$ cells. Immunity (2014) 40:490-500. doi:10.1016/j.immuni.2014.03.003

44. Wilhelm M, Kunzman V, Eckstein S, Reimer P, Weissinger F, Ruediger T, et al. Gammadelta T cells for immune therapy of patients with lymphoid malignancies. Blood (2003) 102:200-6. doi:10.1182/blood-2002-12-3665

45. Kabelitz D, Wesch D, He W. Perspectives of gammadelta T lymphocytes in tumor immunology. Cancer Res (2007) 67:5-8. doi:10.1158/0008-5472.CAN-06-3069

46. Chiplunkar S, Dhar S, Wesh D, Kabelitz D. Gammadelta T cells in cancer immunotherapy: current status and future prospects. Immunotherapy. (2009) 1:663-78. doi:10.2217/imt.09.27

47. Groh V, Wu J, Yee C, Spies T. Tumor-derived soluble MIC ligands impair expression of NKG2D and T cell activation. Nature (2002) 419:734-8. doi:10.1038/ nature01112

48. Kaiser BK, Yim D, Chow I-T, Gonzales S, Dai Z, Mann HH, et al. Disulphideisomerase-enabled shedding of tumor-associated NKG2D ligands. Nature (2007) 447:482-7. doi:10.1038/nature05768

49. Waldhauer I, Goehlsdorf D, Gieseke F, Weinschenk T, Wittenbrink M, Ludwig A, et al. Tumor-associated MICA is shed by ADAM proteases. Cancer Res (2008) 68:6368-76. doi:10.1158/0008-5472.CAN-07-6768

50. Pruessmeyer J, Ludwig A. The good, the bad and the ugly substrates for ADAM10 and ADAM17 in brain pathology, inflammation and cancer. Semin Cell Dev Biol. (2009) 20:164-74. doi:10.1016/j.semcdb.2008.09.005

51. Poggi A, Zancolli M, Boero S, Catellani S, Musso A, Zocchi MR. Differential survival of gammadelta $T$ cells, alphabeta T cells and NK cells upon engagement of NKG2D by NKG2DL-expressing leukemic cells. Int J Cancer (2011) 129:387-96. doi:10.1002/ijc.25682

52. Zocchi MR, Catellani S, Canevali P, Tavella S, Garuti A, Villaggio B, et al. High ERp5/ADAM10 expression in lymph node microenvironment and impaired NKG2D-ligands recognition in Hodgkin lymphomas. Blood (2012) 119:1479-89. doi:10.1182/blood-2011-07-370841

53. Jinushi M, Vanneman M, Munshi NC, Tai YT, Prabhala RH, Ritz J, et al. MICA antibodies and shedding are associated with the progression of multiple myeloma. Proc Natl Acad Sci U S A. (2008) 105:1285-90. doi:10.1073/pnas. 0711293105 
54. Nückel H, Switala M, Sellmann L, Horn PA, Dürig J, Dührsen U, et al. The prognostic significance of soluble NKG2D ligands in B-cell chronic lymphocytic leukemia. Leukemia (2010) 24:1152-9. doi:10.1038/leu.2010.74

55. Tokuyama H, Hagi T, Mattarollo SR, Morley J, Wang Q, Fai-So H, et al. $\mathrm{V} \gamma 9 \mathrm{~V} \delta 2 \mathrm{~T}$ cell cytotoxicity against tumor cells is enhanced by monoclonal antibody drugs-Rituximab and trastuzumab. Int J Cancer (2008) 122:2526-34. doi:10.1002/ijc. 23365

56. Fisher JPH, Heuijerjans J, Yan M, Gustafsson K, Anderson J. $\gamma \delta$ T cells for cancer immunotherapy. A systematic review of clinical trials. Oncoimmunolgy (2014) 3:e27572. doi:10.4161/onci.27572

57. Kunzmann V, Smetak M, Kimmel B, Weigang-Koehler K, Goebeler M, Birkmann J, et al. Tumor-promoting versus tumor-antagonizing roles of $\gamma \delta \mathrm{T}$ cells in cancer immunotherapy: results from a prospective phase I/II trial. J Immunother (2012) 35:205-13. doi:10.1097/CJI.0b013e318245bb1e

58. Braza MS, Klein B. Anti-tumor immunotherapy with V $\gamma 9 \mathrm{~V} \delta 2 \mathrm{~T}$ lymphocytes: from the bench to the bedside. Br J Haematol (2013) 160:123-32. doi:10.1111/bjh.12090

59. Bennouna J, Levy V, Sicard H, Senellart H, Audrain M, Hiret S, et al. Phase I study of bromohydrin pyrophosphate (BrHPP, IPH 1101), a Vgamma9Vdelta2 T lymphocyte agonist in patients with dolid tumors. Cancer Immunol Immunother (2010) 59:1521-30. doi:10.1007/s00262-010-0879-0

60. Skerjanec A, Berenson J, Hsu C, Major P, Miller WH Jr, Ravera C, et al. The pharmacokinetics and pharmacodynamics of zolendronic acid in cancer patients with varying degrees of renal function. J Clin Pharmacol (2003) 43:154-62. doi:10.1177/0091270002239824

61. Gertner-Dardenne J, Bonnafous C, Bezombes C, Capietto AH, Scaglione V, Ingoure $\mathrm{S}$, et al. Bromohydrin pyrophosphate enhances antibody-dependent cell-mediated cytotoxicity induced by therapeutic antibodies. Blood (2009) 113:4875-84. doi:10.1182/blood-2008-08-172296

62. Dieli F, Vermijlen D, Fufaro F, Caccamo N, Meraviglia S, Cicero G, et al. Targeting human gammadelta $\mathrm{T}$ cells with zoledronate and interleukin- 2 for immunotherapy of hormone-refractory prostate cancer. Cancer Res (2007) 67:7450-7. doi:10.1158/008-5472.CAN-07-0199

63. Lang JM, Kaikobad MR, Wallace M, Staab MJ, Horvath DL, Wilding J, et al. Pilot trial of interleukin-2 and zoledronic acid to augment $\gamma \delta \mathrm{T}$ cells as treatment for patients with refractory renal cell carcinoma. Cancer Immunol Immunother (2011) 60:1447-60. doi:10.1007/s00262-011-1049-8

64. Fourniè J-J, Sicart H, Poupot M, Bezombes C, Blanc A, Romagné F, et al. What lessons can be learned from $\gamma \delta \mathrm{T}$ cell-based cancer immunotherapy trials? Cell Mol Immunol (2013) 10:35-41. doi:10.1038/cmi.2012.39

65. Motzer RJ, Escudier B, Oudard S, Hutson TE, Porta C, Bracarda S, et al. Phase 3 clinical trial of everolimus for metastatic renal cell carcinoma: final results and analysis of prognostic factors. Cancer (2010) 116:4256-65. doi:10.1002/ cncr25219

66. Heigener DFD, Wu Y-LY, van Zandwijk N, Mali P, Horwood K, Reck M. Second-line erlotinib in patients with advanced non-small-cell lung cancer: subgroup analyses from the TRUST study. Lung Cancer (2011) 74:274-9. doi:10.1016/j.lungcan.2011.0.017

67. Garassino MC, Martelli O, Broggini M, Farina G, Veronese S, Rulli E, et al. Erlotinib versus docetaxel as second-line treatment of patients with advanced non-small-cell lung cancer and wild type EGFR tumors (TAILOR): a randomized controlled trial. Lancet Oncol (2013) 14:981-8. doi:10.1016/S14702045(13)70-310-3

68. Lee JC, Lee KM, Kim DW, Heo DS. Elevated TGF-betal secretion and downmodulation of NKG2D underlies impaired NK cytotoxicity in cancer patients. $J$ Immunol (2004) 172:7335-40. doi:10.4049/jimmunol.172.12.7335

69. Capietto A-H, Martinet L, Cendron D, Fruchon S, Pont F, Fournié J-J. Phosphoantigen overcome human TCRVgamma9+ gammadelta cell immunosuppression by TGF-beta: relevance for cancer immunotherapy. J Immunol (2010) 184:6680-7. doi:10.4049/jimmunol.1000681

70. Hamid O, Robert C, Daud A, Hodi FS, Hwu W-J, Keffort R, et al. Safety and tumor responses with lambrolizumab (anti-PD-1) in melanoma. $N$ Engl J Med (2013) 369:134-44. doi:10.1065/NEJMoa1305133

71. Hodi FS, O’Day SJ, McDermott DF, Weber RW, Sosman JA, Haanen JB, et al. Improved survival with ipilimumab in patients with metastatic melanoma. $N$ Engl J Med (2010) 363:711-23. doi:10.1056/NEJMoa1003466
72. Kohga K, Takehara T, Tatsumi T, Miyagi T, Ishida H, Ohkawa K, et al. Anticancer chemotherapy inhibits MHC class I-related chain a ectodomain shedding by downregulating ADAM10 expression in hepatocellular carcinoma. Cancer Res (2009) 69:8050-7. doi:10.1158/0008-5472.CAN-09-0789

73. Wu JD, Atteridge CL, Wang X, Seya T, Plymate SR. Obstructing shedding of the immunostimulatory MHC class I chain-related gene B prevents tumor formation. Clin Cancer Res (2009) 15:632-40. doi:10.1158/1078-0432.CCR-08- 1305

74. Wang X, Lundgren AD, Singh P, Goodlett DR, Plymate SR, Wu JD. An sixamino acid motif in the alpha3 domain of MICA is the cancer therapeutic target to inhibit shedding. Biochem Biophys Res Commun. (2009) 387:476-81. doi:10.1016/j.bbrc.2009.07.062

75. Nuti E, Panelli L, Casalini F, Avramova SI, Orlandini E, Santamaria S, et al. Design, synthesis, biological, and NMR studies of a new series of arylsulfones as selective and potent matrix metalloproteinase-12 inhibitors. J Med Chem (2009) 52:6347-61. doi:10.1021/jm900335a

76. Richards FM, Tape CJ, Jodrell DI, Murphy G. Anti-tumour effects of a specific anti-ADAM17 antibody in an ovarian cancer model in vivo. PLoS One (2012) 7:e40597. doi:10.1371/journal.pone.0040597

77. Martinet L, Fleury-Cappellesso S, Gadelorge M, Dietrich G, Bourin P, Fournié JJ, et al. A regulatory cross-talk between Vgamma9Vdelta2 T lymphocytes and mesenchymal stem cells. Eur J Immunol (2009) 39:752-62. doi:10.1002/eji. 200838812

78. Musso A, Zocchi MR, Poggi A. Relevance of the mevalonate biosynthetic pathway in the regulation of bone marrow mesenchymal stromal cell-mediated effects on T-cell proliferation and B-cell survival. Haematologica (2011) 96:16-23. doi:10.3324/haematol.2010.031633

79. Musso A, Catellani S, Canevali P, Tavella S, Venè R, Boero S, et al. Aminobisphosphonates prevent the inhibitory effects exerted by lymph node stromal cells on anti-tumor V $82 \mathrm{~T}$ lymphocytes in non-Hodgkin lymphomas. Haematologica (2014) 99:131-9. doi:10.3324/haematol.2013.097311

80. Todaro M, Meraviglia S, Caccamo N, Stassi G, Dieli F. Combining conventional chemotherapy and $\gamma \delta \mathrm{T}$ cell-based immunotherapy to target cancer-initiating cells. Oncoimmunolgy. (2013) 2:e25821. doi:10.4161/once.25821

81. Wesh D, Peters C, Oberg H-H, Pietschmann K, Kabelitz D. Modulation of $\gamma \delta \mathrm{T}$ cell responses by TLR ligands. Cell Mol Life Sci (2011) 68:2357-70. doi:10.1007/s00018-011-0699-1

82. van der Veken LT, Hagedoorn RS, van Loenen MM, Willemze R, Falkenburg JH, Heemskerk MH. Alphabeta T-cell receptor engineered gammadelta $\mathrm{T}$ cells mediate effective antileukemic reactivity. Cancer Res (2006) 66:3331-7. doi:10.1158/0008-5472.CAN-05-4190

83. Hiasa A, Nishikawa H, Hirayama M, Kitano S, Okamoto S, Choono H, et al. Rapid alphabeta TCR-mediated responses in gammadelta $\mathrm{T}$ cells transduced with cancer-specific TCR genes. Gene Ther (2009) 16(5):620-8. doi:10.1038/gt. 2009.6

84. Palakodeti A, Sandstrom A, Sundaresan L, Harly C, Nedellec S, Olive D, et al. The molecular basis for modulation of human $\mathrm{V} \gamma 9 \mathrm{~V} \delta 2 \mathrm{~T}$ cell responses by CD277/butyrophilin-3 (BTN3A)-specific antibodies. J Biol Chem (2012) 287:32780-90. doi:10.1074/jbc.M112.384354

Conflict of Interest Statement: The authors declare that the research was conducted in the absence of any commercial or financial relationships that could be construed as a potential conflict of interest.

Received: 24 September 2014; paper pending published: 19 October 2014; accepted: 27 October 2014; published online: 11 November 2014.

Citation: Poggi A and Zocchi MR (2014) $\gamma \delta T$ lymphocytes as a first line of immune defense: old and new ways of antigen recognition and implications for cancer immunotherapy. Front. Immunol. 5:575. doi: 10.3389/fimmu.2014.00575

This article was submitted to T Cell Biology, a section of the journal Frontiers in Immunology.

Copyright (C) 2014 Poggi and Zocchi. This is an open-access article distributed under the terms of the Creative Commons Attribution License (CC BY). The use, distribution or reproduction in other forums is permitted, provided the original author(s) or licensor are credited and that the original publication in this journal is cited, in accordance with accepted academic practice. No use, distribution or reproduction is permitted which does not comply with these terms. 